\title{
XX Aniversario de la Revista Venezolana de Gerencia
}

La Revista Venezolana de Gerencia (RVG) este año 2016 arribó a su vigésimo aniversario, momento propicio para encontrar en tiempo y espacio a investigadores de las ciencias sociales y miembros de otras revistas académicas de similar naturaleza para hacer un balance de experiencias, ideas y retos de cara al futuro. El encuentro se dio el pasado 13 de julio y las palabras de apertura estuvieron a cargo de la Magíster Rosana Meleán, editora jefe de la RVG, quien destacó el trabajo pionero que en el año 1996 impulsó a un equipo de investigadores comprometidos con el avance del conocimiento y su divulgación, encabezado por las profesoras Teresa Gamboa y Haydée Ochoa, destacó además el cambio de periodicidad que ha tenido la revista pasando de semestral en sus inicios, a cuatrimestral en 1998 y a trimestral en 2001, para dar respuesta a las necesidades y exigencias. Destacó además el importante papel de personalidades que de uno u otro modo han fungido como impulsores, como es el caso del Dr. Bernardo Kliksberg; además el alcance internacional que ha alcanzado a lo largo de los años, así como los logros y desafíos a los que se enfrenta actualmente, en un contexto de incertidumbre y restricciones económicas.

Seguidamente tuvo su intervención la Magíster Yorberth Montes de Oca, Directora del Centro de Estudios de la Empresa, quien subrayó el aprendizaje sobre la base de la experiencia que se expresa en el carácter multidisciplinario de nuestra RVG, así como el aporte al conocimiento de la gerencia en particular, y las ciencias sociales en general, al constituirse en un espacio de libre pensamiento, autonomía académica, un medio de comunicación e intercambio de ideas y un espacio de entrenamiento para autores y árbitros.

Luego tuvo lugar la intervención del Magíster Ivan Cañizales, Decano de la Facultad de Ciencias Económicas y Sociales (FCES), sus palabras fueron elocuentes para resaltar la importancia y pertinencia del uso intensivo de las tecnologías de información y comunicación, lo cual representa una "ventana abierta las 24 horas" para que la RVG la FCES presente sus resultados y experiencias, destacando el impulso que esto genera a su vez en las actividades de docencia e investigación.

La conferencia internacional estuvo a cargo del Dr. Eduardo Aguado (Director general de Redalyc) quien hizo su disertación sobre la base de un artículo publicado conjuntamente con Ariana Becerril en el pasado número 73 de RVG, titulado: Producción científica venezolana: apuntes sobre su pérdida de liderazgo en la región latinoamericana. Su presentación versó sobre la finalidad de la ciencia, la producción científica venezolana se- 
gún los hallazgos publicados en el mencionado artículo y luego apuntó a las características editoriales de la RVG.

Respecto a la ciencia enfatizó la finalidad de comunicar, transmitir y dialogar los resultados de la investigación y destacó el papel del conocimiento como factor determinante del progreso en los países. Recalcó que la finalidad de una revista científica es conducirconstruir una conversación global, regional, nacional, o local, según sea el caso; construir un diálogo, construir un discurso y una identidad visual. Y como resultado de ese diálogo, de esa participación en la narrativa, la revista asume diversas posturas, en la cual los autores reconocen el alcance de la revista, y por ello quieren escribir en ella; pero además se convierte en punto de referencia en su área disciplinar. Son motivo de orgullo para instituciones, y además son altamente citadas por el reconocimiento que se tiene de ellas.

Respecto a la producción científica venezolana, Aguado calificó la situación venezolana como desesperada citando un artículo publicado en la revista sciencie. Destacó que Venezuela es el único país en América Latina cuya producción científica está disminuyendo, cuestión que resulta contradictoria a la media regional que crece significativamente en bases de datos internacionales, principalmente en países como Brasil. Chile, y Colombia, tal aseveración la soporta en los resultados que refleja SCOPUS y Redalyc en los últimos veinte años, cuya tendencia demuestra un crecimiento sostenido desde 1996 hasta 2009 con un punto de quiebre en el 2014. Señala además que la crisis no es sólo de la producción venezolana, sino también de las revistas venezolanas, por tanto reflexiona sobre la necesidad de instrumentar estrategias para reforzarlas.

El último punto que desarrolló fue las características editoriales de la RVG en una serie de diez años, en la cual presentó un balance de indicadores tales como procedencia de artículos y evolución de la participación interna y externa, número de descargas, entre otros. Las tendencias demuestran que RVG se ha consolidado de forma significativa, sin embargo, requiere incorporar nuevas estrategias al modelo de divulgación científica.

La segunda conferencia estuvo a cargo de la Dra Haydee Ochoa quien presentó en coautoría con la Magíster Elizabeth Boscan, una disertación titulada: Conocimiento alternativo en Venezuela. El reto de las revistas científicas. Estrategia fundamental para la visibilidad. Ochoa plantea que la RVG ha permitido la visibilidad de la Universidad del Zulia en las bases de datos, y esto se evidencia en descargas. Destacó además las oportunidades que presentan los repositorios y otras bases de datos que permiten sistematizar la productividad, además que es una forma de hacer frente a la escasez de recursos económicos.

Hizo énfasis en la necesidad de dar cabida al pensamiento alternativo, es decir aquel que es distinto a la corriente principal del conocimiento, y que considera invisibiliza ese conocimiento alternativo con una pretensión de neutralidad, y por tanto, no es tomado en cuenta en las bases de datos internacionales tales como SCI, SCOPUS y google. Señala entonces la necesidad de dar cabida al conocimiento plural, pues algunas publicaciones sólo admiten pensamiento contrahegemónico. 
Considera que evaluar la producción científica de un país requiere conocer el contexto y no hacerlo sobre la base de registros como Scopus. Hizo referencia a una serie de políticas gubernamentales de apoyo a la actividad científica como es el caso del Programa de promoción del Investigador (PPI) como una estrategia de reproducción de la corriente principal de la ciencia que sufrió cambios en el año 2002 para ampliar los índices, conservando los criterios de la corriente principal. En el año 2010 se suspendió el apoyo financiero en el contexto de la crisis de cumplimiento de la política científica. En el 2011 se cierra el PPI y se abre el Programa de Estímulo a la Investigación (PEI) con criterios que valoran la transformación de la realidad; lo que adquiere especial importancia para el proceso de innovación. De esta forma se incorporan nuevos sujetos, se articulan investigadores y usuarios, y se definen áreas prioritarias como ocurre con el caso de la misión ciencia. De lo anterior se desprende la oferta de financiamiento para la investigación articulada con el plan nacional Simón Bolívar. Añade que Venezuela ha desarrollado una política editorial de producción de conocimiento como es el caso de la librería del Sur y el premio libertador.

Finaliza su disertación destacando la que las revistas científicas están llamadas a abrir espacios de investigación alternativo haciendo referencia a los criterios de inclusión del índice venezolano Clacalia.

A partir de ello, se abrió espacio para la discusión entre los presentes, donde se plantearon como temas asociados la necesidad imperiosa de impulsar la conformación de redes de investigadores, de construir repositorios, que además se conviertan en un punto de apoyo para la RVG, la importancia de dar cabida a investigaciones de conocimiento alternativo conjuntamente con investigación de la denominada corriente principal. La Dra. Ochoa propuso como estrategia que la RVG abra un apartado para sistematización de experiencias y de esta forma conciliar las exigencias de ambos tipos de conocimiento.

Para finalizar la jornada la profesora Rosana Meleán narró las experiencias previas a propósito de la conformación de la Red venezolana de Revistas Científicas (REVERCI), y dio lectura de algunos aspectos clave del documento formal que se ha redactado para tal fin. La profesora Meleán cerró la jornada agradeciendo la participación de los asistentes y de los miembros de la RVG resaltando la necesidad de afrontar desafíos y superar debilidades.

\author{
Dra. Wendolín Suárez Amaya \\ Miembro del Comité Editorial \\ Revista Venezolana de Gerencia
}

